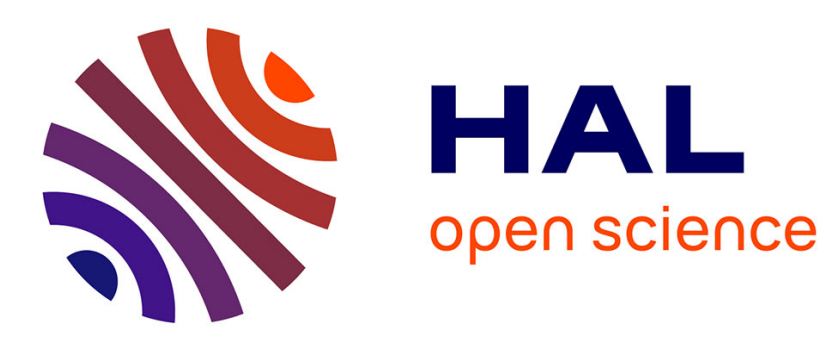

\title{
Diffusion constants of sulfur in the Fe-Ni 36 alloy determined by AES study of surface segregation
}

L. Ben Mostefa, D. Roptin, G. Saindrenan

\section{To cite this version:}

L. Ben Mostefa, D. Roptin, G. Saindrenan. Diffusion constants of sulfur in the Fe-Ni 36 alloy determined by AES study of surface segregation. Revue de Physique Appliquée, 1988, 23 (7), pp.1297-1304. 10.1051/rphysap:019880023070129700 . jpa-00245944

\section{HAL Id: jpa-00245944 https://hal.science/jpa-00245944}

Submitted on 1 Jan 1988

HAL is a multi-disciplinary open access archive for the deposit and dissemination of scientific research documents, whether they are published or not. The documents may come from teaching and research institutions in France or abroad, or from public or private research centers.
L'archive ouverte pluridisciplinaire HAL, est destinée au dépôt et à la diffusion de documents scientifiques de niveau recherche, publiés ou non, émanant des établissements d'enseignement et de recherche français ou étrangers, des laboratoires publics ou privés. 


\title{
Diffusion constants of sulfur in the Fe-Ni 36 alloy determined by AES study of surface segregation
}

\author{
L. Ben Mostefa, D. Roptin and G. Saindrenan \\ Laboratoire Surfaces et Interfaces, U.A. 788, 1 rue de la Noë, 44072 Nantes Cedex 03, France
}

(Reçu le 25 novembre 1987, révisé le 26 février 1988, accepté le 24 mars 1988)

\begin{abstract}
Résumé. - Les coefficients de diffusion du soufre dans les alliages austénitiques Fe-Ni (36) ont été déterminés dans un intervalle de températures allant de $600^{\circ} \mathrm{C}$ à $1000^{\circ} \mathrm{C}$, sur des matériaux industriels, à partir de l'étude de la ségrégation superficielle du soufre par spectroscopie d'électrons Auger (AES). L'expression du coefficient de diffusion en fonction de la température est donnée par: $D_{\mathrm{V}}\left(\mathrm{cm}^{2} \mathrm{~s}^{-1}\right)=$ $26,8 \exp (-261400 \mathrm{~J} / \mathrm{mole}) / R T)$. L'énergie d'activation déterminée $(261,4 \mathrm{~kJ} / \mathrm{mole})$ est légèrement supérieure à celles concernant la diffusion du soufre dans le fer $\gamma$ pur, le nickel pur et les alliages $\mathrm{Fe}-\mathrm{Ni} 25,50$ et $75 \%$ de nickel. Néanmoins, cette valeur permet d'envisager un mécanisme de diffusion lacunaire.

Abstract. - Diffusivity constants of sulfur in austenitic Fe-Ni 36 alloy have been determined at temperatures between $600{ }^{\circ} \mathrm{C}$ and $1000^{\circ} \mathrm{C}$, on industrial materials, from surface segregation studies by Auger Electron Spectrocopy (AES). The temperature dependence of the bulk diffusion constant is given by : $D_{\mathrm{V}}\left(\mathrm{cm}^{2} \mathrm{~s}^{-1}\right)=$ $26.8 \exp (-261400(\mathrm{~J} / \mathrm{mole}) / R T)$. The activation energy $(261.4 \mathrm{~kJ} / \mathrm{mole})$ determined by this method is slightly larger than those associated with sulfur diffusion in pure iron $(\mathrm{Fe} \gamma)$, pure nickel and the $\mathrm{Fe}-\mathrm{Ni} 25,50$ and 75 alloys. Nevertheless, this value allows us to consider a vacancy mechanism diffusion.
\end{abstract}

\section{Introduction.}

At high temperatures, the composition of the free surface of a diluted alloy is generally different from its bulk composition. This is caused by surface segregation. The metalloidic impurities (or alloying elements) can segregate to solid free surfaces (or grain boundaries), if the temperature is adequate to allow atomic motion.

Interfacial segregations of impurities in pure metals have received widespread attention during the last ten years, in relation to the development of surface segregation techniques (especially Auger Electron Spectroscopy (AES)), and because of the consequences of the phenomenon on mechanical and chemical properties of metals. In the case of nickel, superficial and intergranular segregations of sulfur are known to enhance corrosion and to weaken the mechanical properties of the metal due to the intergranular brittleness. For segregation in concentrated nickel alloys, data are less numerous. Marcus et al. have studied the adsorption of sulfur (segregation and chemisorption) on single crystals of various composition $\mathrm{Fe}-\mathrm{Ni}$ alloys [1]. These alloys suffer a hot ductility drop $\left(700^{\circ} \mathrm{C}-1100^{\circ} \mathrm{C}\right)$ due to a high temperature intergranular cavitation and cracking [2] which seems to be in direct relation to interfacial segregations of metalloidic impurities [3]. Otherwise, segregation is restricted by diffusional dependence in solid phase, because atomic flow appears to satisfy a thermodynamic equilibrium between interfacial and bulk material composition.

AES measurements have been successfully used to determine the diffusion constants for several impurities in various binary and more complex systems [4-6]. This method is advantageous to measure diffusion constants (as low as $10^{-20} \mathrm{~cm}^{2} \mathrm{~s}^{-1}$ ), in addition to its rapidity in comparison to other methods such as gravimetric or those using radiotracer elements.

However, the starting state for segregation and the boundary conditions between the surface layer and the adjacent bulk must both be known to resolve Fick's second law. Many theoretical models have been proposed to take into account these conditions ; they often develop numerical integration methods of Fick's laws [7]. When there is no evaporation at the free surface and when the initial state of segregation is a homogeneous solid solution without segregation 
$\left(C_{\mathrm{S}}(t=0)=C_{\mathrm{S}}(0) \simeq 0\right)$, an analytical solution of Fick's equation can be obtained assuming that bulk composition near the surface $C_{\mathrm{V}}(x=0, t)$ remains constant during the segregation process [8]. In this case, the segregation is only controlled by bulk diffusion and consequently the evolution of the surface solute concentration is described by the following relation :

$$
\begin{aligned}
C_{\mathrm{S}}(t)=C_{\mathrm{S}}(0)+2\left[C_{\mathrm{V}}(x=\infty)-\right. & \left.C_{\mathrm{V}}(x=0, t)\right] \\
& \times \sqrt{\frac{D_{\mathrm{V}} t}{\pi}}
\end{aligned}
$$

where

$$
\begin{aligned}
& C_{\mathrm{V}}(x=\infty): \text { is the initial solute bulk concen- } \\
& \text { tration } \\
& C_{\mathrm{V}}(x=0, t): \text { is the solute bulk concentration in }
\end{aligned}
$$

Bulk concentrations are expressed in atoms per unit volume and surface concentration in atoms per unit surface.

In this relation, valid only in isothermal conditions, the quantity $C_{\mathrm{V}}(x=0, t)$ is assumed to be constant whatever the time is. In practise, the value of $C_{\mathrm{V}}(x=0, t)$ generally increases with $C_{\mathrm{S}}(t)$ values; so, from the above mentioned assumptions $\left(C_{\mathrm{V}}(x=0, t)=\right.$ constant $)$, it follows that the relation (1) is valid only in the case where the segregation is described by a Fowler-Guggenheim's isotherm ; i.e., when there is an attractive interaction between sulfur and metal atoms. Moreover, this quantity becomes negligible relative to $C_{\mathrm{V}}(x=\infty)$, whatever the shape of the segregation isotherm is, in two practical cases [6] :

- for low surface coverages,

- when the metal is oversaturated in solute.

In addition, if the starting state is a surface without segregation (by ionic cleaning), the relation (1) is reduced to :

$$
C_{\mathrm{S}}(t)=2 C_{\mathrm{V}} \sqrt{\frac{D_{\mathrm{V}} \cdot t}{\pi}}
$$

The relation (2) has also been proposed by Lea and Seah [9] from the grain boundary segregation of McLean's equation [10]. From a known bulk solid solution composition $C_{\mathrm{V}}(x=\infty)$, the solute diffusion constant $D_{\mathrm{V}}$ can be easily determined from segregation kinetics using relation (2).

From the above mentioned assumptions, we propose to determine the sulfur diffusion characteristics in the $\mathrm{Fe}-\mathrm{Ni} 36$ alloy by using the surface segregation kinetics of this element, after some considerations about the segregation of several metalloidic impurities. This study was carried out over the range of temperature from $600{ }^{\circ} \mathrm{C}$ to $1000^{\circ} \mathrm{C}$.

\section{Materials and experimental procedure.}

The Fe-Ni 36 alloy used in the present study is an industrial material manufactured by Imphy S.A. as a thin strip. Its chemical composition is listed in table I. The sulfur bulk concentration ( $18 \mathrm{ppm} \mathrm{wt)}$ is larger than the solubility limit at room temperature at which sulfide precipitates are observed by electronic microscopy [11]. The data concerning the equilibrium diagram of the $\mathrm{Fe}-\mathrm{Ni}-\mathrm{S}$ system are scarce. It is known that :

- for the Fe-Ni 75 alloy the solubility limit is $42 \mathrm{ppm}$ at $1150^{\circ} \mathrm{C}$ [1],

- for the Fe-Ni 50 alloy it is $36 \mathrm{ppm}$ and $56 \mathrm{ppm}$ at $1180^{\circ} \mathrm{C}$ and $1200^{\circ} \mathrm{C}$ respectively [12].

These data cannot be used for the present alloy, so we have verified experimentally the presence of sulfides in the alloy after annealing at $1000{ }^{\circ} \mathrm{C}$ and $1100{ }^{\circ} \mathrm{C}$ for 3 and $1 \mathrm{~h}$ respectively; after annealing the alloys were quenched in cold water and the presence of sulfides was detected by optical microscopy after a piquration test which exclusively reveals the sulfide precipitates [11].

These materials also exhibit fine boron nitride precipitates in spite of the low concentration of nitrogen and boron in the alloy [11].

The specimens were cold rolled to about $0.8 \mathrm{~mm}$ thickness, then polished and rinsed in pure acetone. After a chemical cleaning in sulfuric acid solution at $60{ }^{\circ} \mathrm{C}$, they were homogenised by recrystallisation annealing for $30 \mathrm{~min}$ at $850{ }^{\circ} \mathrm{C}$ (according to Imphy S.A. procedure) in evacuated quartz capsules under pure argon atmosphere and then cut into a rectangular form of $4 \mathrm{~mm} \times 3 \mathrm{~mm}$ for the Auger analysis.

The Auger electron spectroscopy (AES) system consists of a Riber ISA model ASC 2000 analyser with a cylindrical mirror analyser and coaxial gun. The sample is spot welded to a strip of tantalum heated by electrical resistance inside the Auger

Table I. - The chemical composition of the Fe-Ni 36 alloy in wt. \%.

\begin{tabular}{|c|c|c|c|c|c|c|c|c|c|c|c|}
\hline $\mathrm{C}$ & $\mathrm{Si}$ & $\mathrm{S}$ & $\mathrm{P}$ & $\mathrm{Mn}$ & $\mathrm{Ti}$ & $\mathrm{Al}$ & $\mathrm{Ca}$ & $\mathrm{B}$ & $\mathrm{Mg}$ & $\mathrm{N}$ & $\mathrm{Ni}$ \\
\hline 0.027 & 0.12 & 0.0018 & 0.003 & 0.29 & $<0.005$ & $<0.005$ & 0.012 & 0.0009 & $<0.001$ & $<0.0005$ & 35.84 \\
\hline
\end{tabular}


vacuum system, samples being heated by conduction from the strip. The temperature is measured with thin wire $(50 \mu \mathrm{m})$ thermocouples (chromel-alumel) spot welded to the sample. Such a device allows temperature to rise to $1000{ }^{\circ} \mathrm{C}$ within a minute. The basic residual pressure in the chamber is maintained below $5 \times 10^{-8} \mathrm{~Pa}$. Typical parameters for Auger measurements are : $3 \mathrm{keV}$ primary energy, $0.1 \mu \mathrm{A}$ primary beam current and about $1 \mu \mathrm{m}$ for the beam diameter. The Auger spectra are recorded, and the peak to peak heights, measured in the derivative mode, are reported in $\left(C_{\mathrm{S}}, t\right)$ diagram for each studied temperature. The sulfur surface concentration is determined from the following calibration :

We chose as characteristic peaks, the nickel $(848 \mathrm{eV})$ and the iron $(650 \mathrm{eV})$. We have not retained the $703 \mathrm{eV}$ iron peak, although it is the most intense, because it is disturbed by the proximity of 676,709 and $716 \mathrm{eV}$ nickel peaks. Nickel is more sensitive to the Auger effect than iron ; the measured peak heights from each pure element are in the ratio $H_{\mathrm{Ni}}^{0} / H_{\mathrm{Fe}}^{0}=1.3$. Taking nickel as a reference we have normalized the peak height $H_{\mathrm{S}}$ to the value of $\left(1.3 H_{\mathrm{Fe}}+H_{\mathrm{Ni}}\right)$. Thus the sulfur concentration is obtained from

$$
C_{\mathrm{S}}=\alpha \cdot \frac{H_{\mathrm{S}}}{1.3 H_{\mathrm{Fe}}+H_{\mathrm{Ni}}} \cdot d_{\mathrm{S}}\left(\text { at. } \mathrm{cm}^{-2}\right) .
$$

In this relation,

- $\alpha$ is a constant depending on the Auger analyser ;

- $H_{\mathrm{S}}, H_{\mathrm{Fe}}$ and $H_{\mathrm{Ni}}$ are the usual peak heights measured in the derivative mode ;

$-d_{\mathrm{S}}$ is the atomic density of the surface of a polycrystalline $\mathrm{Fe}-\mathrm{Ni} 36$ alloy.

The calculations of the constant $\alpha$ are made assuming that the sulfur segregates in the first atomic layer ; thus it can be calculated using the following equation [13]

$$
\alpha=\left[\frac{H_{\mathrm{S}}^{0}}{H_{\mathrm{MAT}}^{0}}\right]^{-1} \cdot\left[1-\exp \left(\frac{-a}{\lambda \cdot \cos \theta}\right)\right]^{-1}
$$

where

- $H_{\mathrm{S}}^{0}$ is the Auger peak height of the pure sulfur ;

$-H_{\mathrm{MAT}}^{0}=1.3 H_{\mathrm{Fe}}^{0}+H_{\mathrm{Ni}}^{0}$ where $H_{\mathrm{Fe}}^{0}, H_{\mathrm{Ni}}^{0}$ are the Auger peak heights of the pure element ;

$-a$ is the segregated thickness;

$-\lambda$ is the mean free path of the Auger electron emitted by the sulfur atoms;

- $\theta$ is the emergence angle of the Auger electron out of the used cylindrical mirror analyser. $H_{\mathrm{Fe}}^{0}$, $H_{\mathrm{Ni}}^{0}$ and $H_{\mathrm{S}}^{0}$ come from [14]. We chose the same values for $a$ and $\lambda(a=0.25 \mathrm{~nm}, \lambda=0.5 \mathrm{~nm})$ as those used by Larere [15] in the case of sulfur segregation in pure nickel. $\cos \theta=0.74$. For a $\mathrm{Fe}-\mathrm{Ni}$ 36 alloy we assume that the matrix signal $H_{\mathrm{MAT}}^{0}$ is proportional to the concentration of each element i.e. $H_{\mathrm{MAT}}^{0}=1.3 \times 0.64 H_{\mathrm{Fe}}^{0}+0.36 H_{\mathrm{Ni}}^{0}$. In these conditions the value of $\alpha$ is $0.38 \pm 0.03$. If $a^{3}$ is the atom volume ; the atomic density $d_{\mathrm{S}}$ is $a^{-2}$, its value is $19.5 \times 10^{14}$ at. $\mathrm{cm}^{-2}$ with a lattice parameter of $0.359 \mathrm{~nm}$ for this f.c.c. alloy [16].

\section{Experimental results.}

Figure 1 shows Auger spectra at $600{ }^{\circ} \mathrm{C}$ and $700{ }^{\circ} \mathrm{C}$. In our experimental conditions, we observe that phosphorus $(120 \mathrm{eV})$ remains on the surface even after $6 \mathrm{~h}$ annealing at $600{ }^{\circ} \mathrm{C}$ (spectrum A), but at $700{ }^{\circ} \mathrm{C}$ we can observe a surface free of phosphorus after $7 \mathrm{~h}$ of annealing (spectrum B). The nitrogen $(380 \mathrm{eV})$ and boron $(172 \mathrm{eV})$ do not segregate during the various heat treatments up to $1000{ }^{\circ} \mathrm{C}$; they are observed on the surface only during a second isothermal annealing series following the $1000{ }^{\circ} \mathrm{C}$ annealing (spectrum $\mathrm{C}$ ). In addition to previous remarks, we readily observe sulfur, nickel and iron peaks on the spectra.

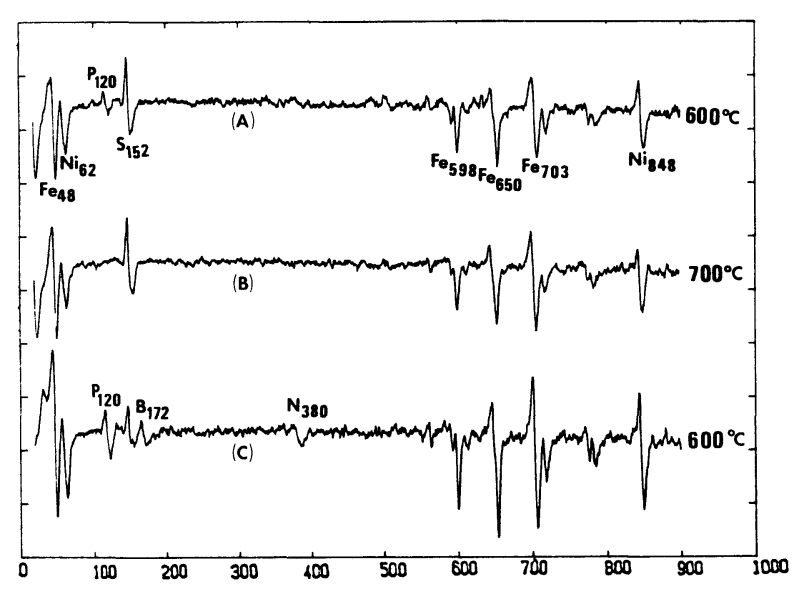

Fig. 1. - AES spectra : (A) $600{ }^{\circ} \mathrm{C}-6 \mathrm{~h}$; (B) $700{ }^{\circ} \mathrm{C}-7 \mathrm{~h}$; (C) $600{ }^{\circ} \mathrm{C}-6 \mathrm{~h}$.

Figure 2 illustrates the time dependence of both sulfur and phosphorus surface concentrations at $600{ }^{\circ} \mathrm{C}$ and $700{ }^{\circ} \mathrm{C}$ respectively. We observe that, at $600{ }^{\circ} \mathrm{C}$, phosphorus cosegregates on the free surface with sulfur even after $20 \mathrm{~h}$ annealing and its signal is greater than that of sulfur. At $700{ }^{\circ} \mathrm{C}$ the phosphorus is present on the surface only during the first $3 \mathrm{~h}$.

Figure 3 shows the sulfur concentration versus $\sqrt{t}$ in isothermal conditions at $600^{\circ} \mathrm{C}$. The full curve A represents the first kinetic segregation after the introduction of the specimen in the analyser chamber, while the dashed curve B concerns the isothermal kinetics at $600{ }^{\circ} \mathrm{C}$ after the whole segregation treatments of the specimen up to $1000^{\circ} \mathrm{C}$ have been done. The kinetic $B$ is slower than that for A. We think that the curve $A$, corresponding to the 


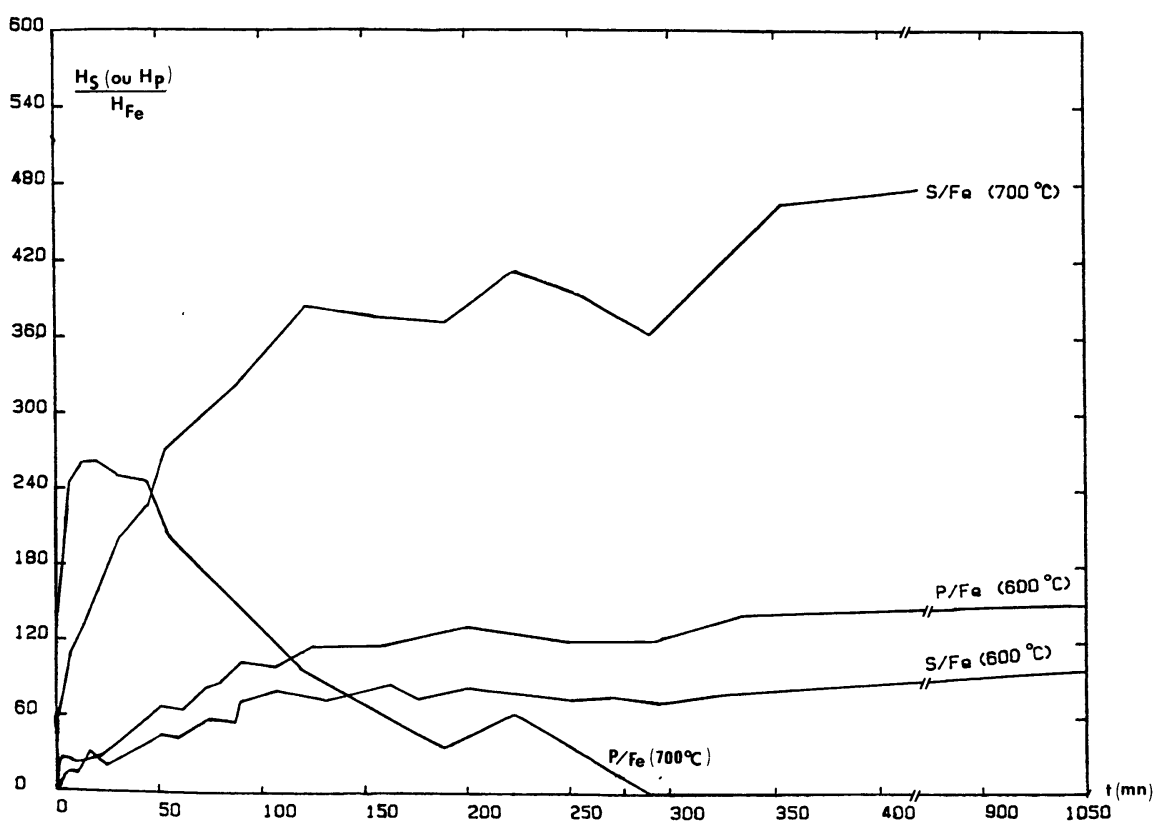

Fig. 2. - Segregation kinetic laws of phosphorus and sulfur at 600 and $700{ }^{\circ} \mathrm{C}$.

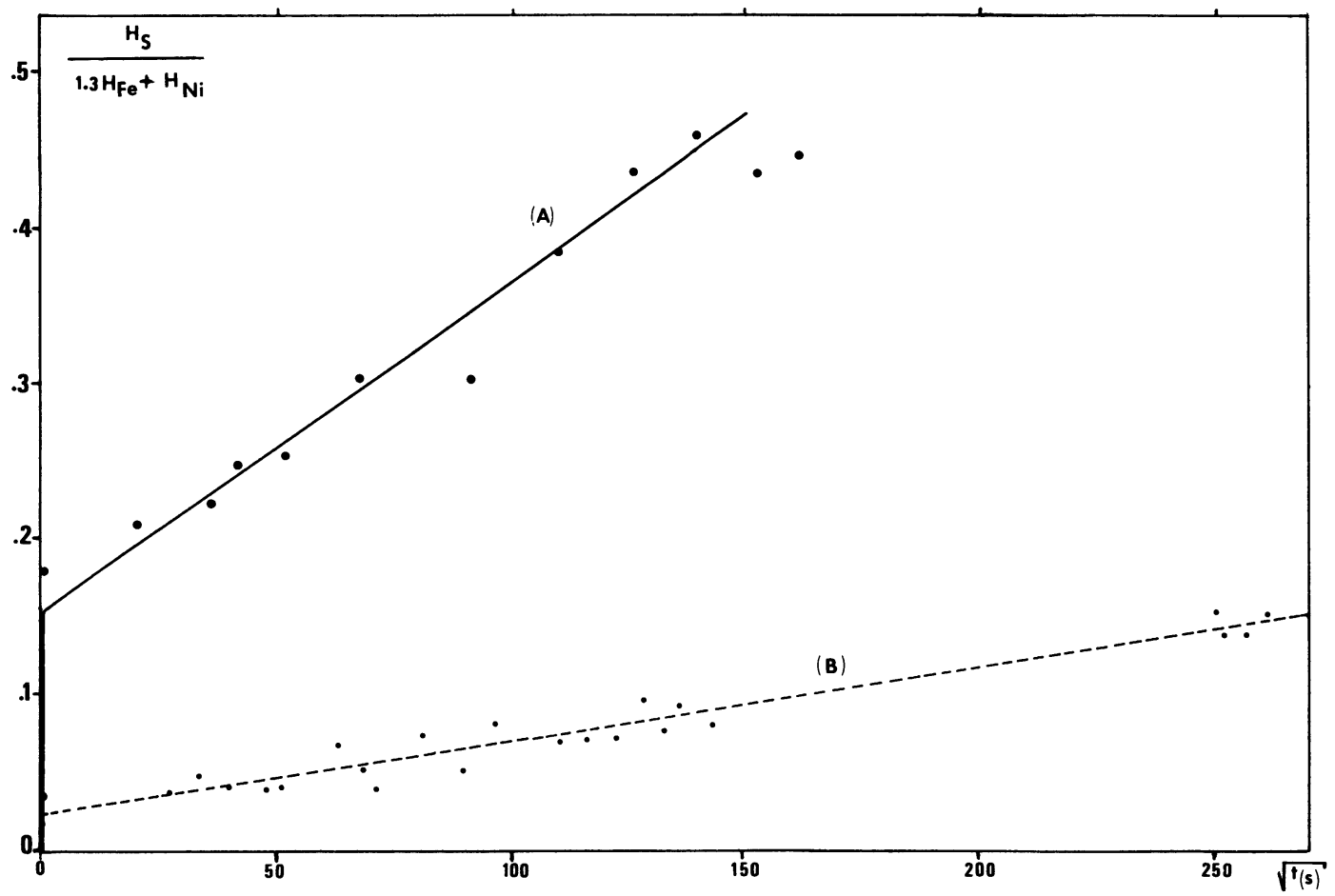

Fig. 3. - Surface concentration of sulfur at $600^{\circ} \mathrm{C}:$ (A) during the first annealing; (B) after the treatments up to $1000^{\circ} \mathrm{C}$.

first heating of the sample after its preparation, accounts for a non-equilibrium segregation mechanism due to slight cold working, resulting from various manipulations of the sample. Indeed, an appreciable sulfur superficial concentration is obtained after a short heating time (one minute); this typical behaviour (fast segregation) has already been observed on pure nickel preliminarily quenched or cold worked [17]. For the next calculations, we shall consider only the kinetics of curve $B$ which seem to correspond to equilibrium segregation.

Figure 4 shows the segregation kinetics for the temperature range studied. The $C_{\mathrm{S}}(t)$ laws are linear with $\sqrt{t}$ and the regression of the calculated 


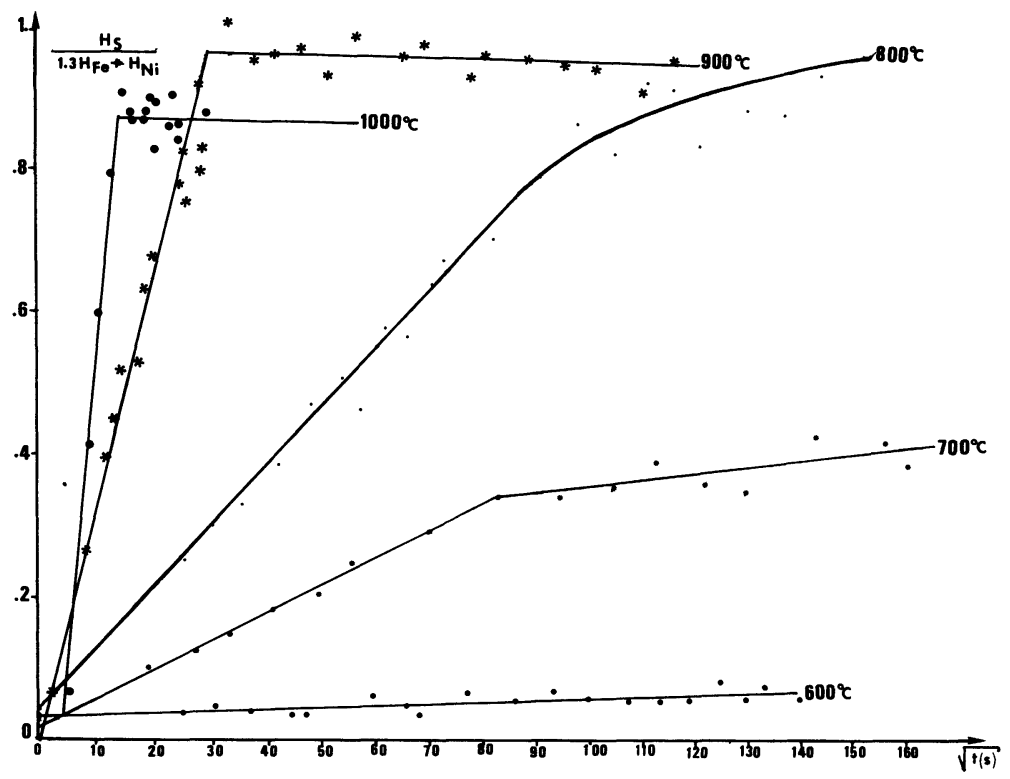

Fig. 4. - Variations of the sulfur surface concentration versus $\sqrt{t}$ at different temperatures.

Table II. - The diffusion constant values calculated between 600 and $1000{ }^{\circ} \mathrm{C}$.

\begin{tabular}{|c|c|c|c|c|c|}
\hline Temperature $^{\circ} \mathrm{C}$ & 600 & 700 & 800 & 900 & 1000 \\
\hline$D_{\mathrm{V}}\left(\mathrm{cm}^{2} \mathrm{~s}^{-1}\right)$ & $1.48 \times 10^{-14}$ & $2.62 \times 10^{-13}$ & $5.09 \times 10^{-12}$ & $6.94 \times 10^{-11}$ & $4.99 \times 10^{-10}$ \\
\hline
\end{tabular}

laws gives correlation constants greater than 0.98 . The concentrations reached at $900{ }^{\circ} \mathrm{C}$ and $1000^{\circ} \mathrm{C}$ are stable; otherwise, their levels decrease when temperature increases. This conforms to the thermodynamic equation proposed by McLean [10].

According to equation (2), $C_{S}(t)$ is the surface concentration of sulfur (atm. $\mathrm{cm}^{-2}$ ), and the $D_{\mathrm{V}}$ values are developed from experimental slopes of the curves reported in figure 4 .

The bulk concentration is $2.752 \times 10^{18} \mathrm{~atm} . \mathrm{cm}^{-3}$ corresponding to $18 \mathrm{ppm}$ wt. The calculated values of diffusion constants $D_{\mathrm{V}}$ are reported in table II and plotted on the Arrhenius diagram of the figure 5. It can be seen that the $600{ }^{\circ} \mathrm{C}$ value is not in alignment with the others. We think that this is the result of a considerable quantity of phosphorus, boron and nitrogen on the surface and it seems reasonable to consider this experimental point as peculiar in comparison with the others. Under these conditions, a straight line calculated in the Arrhenius diagram, from points at $700,800,900$ and $1000^{\circ} \mathrm{C}$, is represented by the following relation :

$$
\begin{aligned}
D_{\mathrm{V}}\left(\mathrm{cm}^{2} \cdot \mathrm{s}^{-1}\right) & = \\
& =26.8 \exp (-261400(\mathrm{~J} / \mathrm{mole}) / R T) .
\end{aligned}
$$

With a correlation constant exceeding 0.99 .

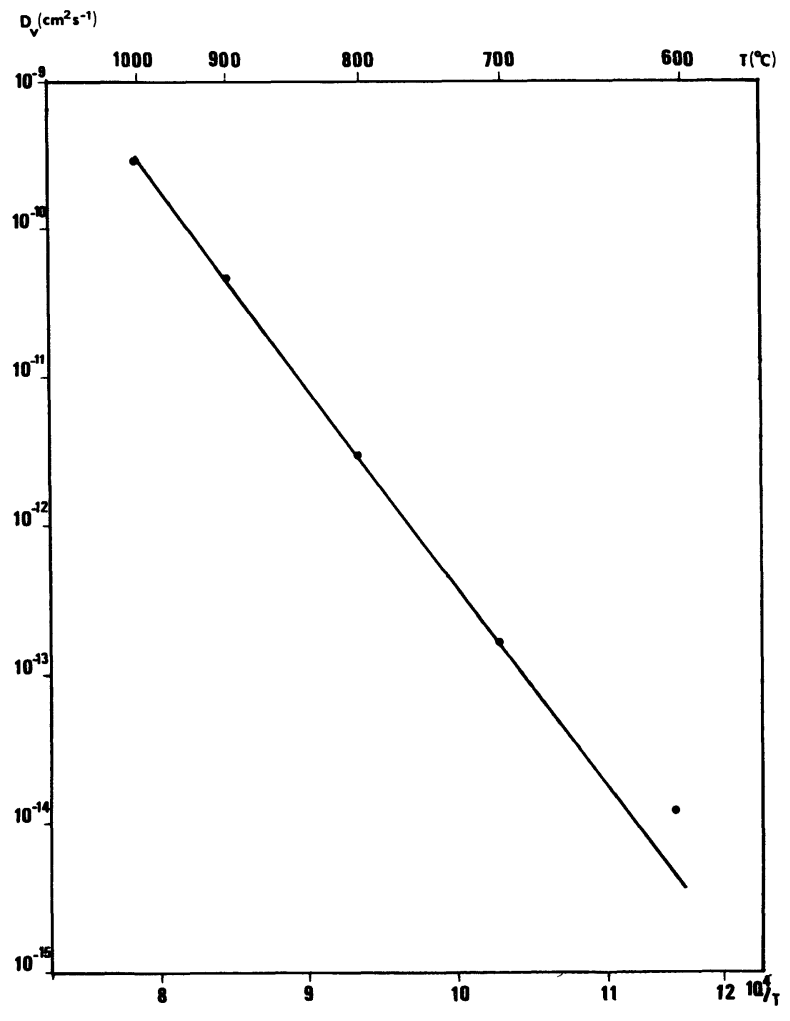

Fig. 5. - Temperature dependence of sulfur diffusion constants in the Fe-Ni 36 alloy. 


\section{Discussion of results.}

The validity of the determined results is limited by various phenomena we have mentioned and which must been reviewed.

4.1 SEgREgation OF OTHER METALlOIDIC ELEMENTS. - The nature of the segregated elements depends both on the material thermal history and the temperature level reached. The curves of figure 3 show the isothermal segregation kinetics of sulfur at $600{ }^{\circ} \mathrm{C}$ for the alloy annealed in the following conditions :

- 30 min annealing at $850^{\circ} \mathrm{C}$ (curve A);

- the previous treatment followed by a series of isothermal annealings at temperature range between 600 and $1000^{\circ} \mathrm{C}$ (curve B).

The difference in the curve slopes can be due to both non-equilibrium phenomena (see paragraph 4.2) and to the metalloid segregation of the other elements. The spectra corresponding to curve B exhibit, in addition to sulfur peak, phosphorus, boron, and nitrogen peaks as showed on the spectrum $\mathrm{C}$ in figure 1 . The energy difference $(7 \mathrm{eV})$ of the boron peak likely evokes a cosegregation of this element with nitrogen. Furthermore, these elements are only present on the surface of the alloy which has been annealed at $1000{ }^{\circ} \mathrm{C}$ prior to the segregation treatment ; this can be explained by a total or partial dissolution of the boron nitride precipitates.

The behaviour of phosphorus is the same as that already described for pure nickel by Larere [15]: because of its strong diffusivity, phosphorus appears more quickly than sulfur at the alloy surface. In isothermal conditions at $600{ }^{\circ} \mathrm{C}$, the presence of both elements on the surface seems to be a stable situation. This hypothesis, which is based only on the kinetic curve shape (stability of surface concentrations after $20 \mathrm{~h}$ of annealing), needs to be verified. In contrast, at $700{ }^{\circ} \mathrm{C}$, the equilibrium thermodynamic situation of the system is expressed by an exclusive sulfur layer on the alloy surface, after a transitional period during which there is coexistence of sulfur and phosphorus on the surface for the kinetic reason mentioned above (the faster diffusion of phosphorus). Similarly to the observations of Larere in the case of nickel, we assumed that the disappearance of phosphorus out of the surface is caused by the redissolution of this element in the matrix.

4.2 NATURE OF SUlfur SEgREgation. - The curves of figure 3 obtained in isothermal conditions at $600{ }^{\circ} \mathrm{C}$ reveal the precautions that should be taken to describe, by the model of McLean, the kinetic and thermodynamic aspects of the experimental segregation. Although the sample was annealed prior to analysis, the first curve obtained at $600{ }^{\circ} \mathrm{C}$ is charac- teristic of a dynamic segregation activated by the elimination of non-equilibrium defects (dislocations, vacancies). Indeed, from the curve $A$ of figure 3 we observe a first stage limited to about one minute, during which sulfur enrichment of the surface is very fast, followed by a second stage (quasi-linear versus $\sqrt{t}$ ) whose kinetic slope is greater than the equilibrium slope represented by the curve B. Similar observations have been done on pure nickel which was preliminarily cold worked. These variations in surface segregation kinetics of sulfur have not been fully explained. However, we can affirm that for the preliminarily cold worked pure nickel, an appreciable segregation is associated to recrystallisation of metal. These segregations go on at high temperatures, by a process $10^{2}$ to $10^{4}$ times faster than the classic diffusional process; this second stage is concurrent with the growth of material grains [18]. In the present case, there is no uniform cold working of the metal, but it seems certain that the manipulations of the sample, especially those due to welding operations, have induced a partial cold working.

4.3 SULFUR DIFFUSION. - The hypotheses to obtain kinetic equation (1) have been discussed in paragraph 1 . In the present case, we have verified that the sulfur concentration is greater than the solubility of sulfur in alloy up to $1000{ }^{\circ} \mathrm{C}$; this observation validates the use of equation (2); this implies that the value of $C_{\mathrm{v}}$ is less than $18 \mathrm{ppm}$ because only the dissolved atoms of sulfur are concerned by the segregation. Furthermore, the solubility of sulfur varies with the temperature and we do not know this law. This inaccuracy of $C_{\mathrm{V}}$ values is the main cause of error in the $D_{\mathrm{V}}$ calculated values and because we do not know the errors on $C_{\mathrm{V}}$ values, we cannot state precisely what are the errors on $D_{\mathrm{v}}$. From data published by Netter et al. [19], it is known that the sulfur solubility in the Fe-Ni 50 alloy is greater than $12 \mathrm{ppm}$ at $950^{\circ} \mathrm{C}$. From our experiments, we know that $18 \mathrm{ppm}$ of sulfur cannot be dissolved after $3 \mathrm{~h}$ at $1000{ }^{\circ} \mathrm{C}$. For lower temperatures we have no values ; if we assume that the solubility of sulfur is $10 \mathrm{ppm}$ at $600^{\circ} \mathrm{C}$ (the same value as in pure nickel [15]), $14 \mathrm{ppm}$ at $1000{ }^{\circ} \mathrm{C}$ and then a linear interpolation of the solubility with the temperatures between $600^{\circ} \mathrm{C}$ and $1000^{\circ} \mathrm{C}$, the so calculated $Q$ value decreases slightly while the $D_{0}$ variation becomes important $\left(D_{0}=8.61\right)$; its value conforms better to the theoretical value calculated from Zener's theory $\left(D_{0} \approx 1\right)$ [25]. Because of the $C_{\mathrm{V}}$ value used, we can say that the calculated values of $D_{\mathrm{V}}$ are greater than the true ones. A more accurate determination of the diffusion constants would require the variation law of the sulfur solubility in the Fe-Ni 36 alloy.

Although the kinetic relation at $600{ }^{\circ} \mathrm{C}$ represented by the curve $B$ in figure 3 seems conform to McLean's modeled conditions, the simultaneous 
Table III. - The sulfur diffusion characteristic in $\mathrm{Fe} \gamma, \mathrm{Ni}$ and $\mathrm{Fe}-\mathrm{Ni}$ alloys.

\begin{tabular}{|c|c|c|c|}
\hline Material & $\begin{array}{c}\text { Temperature } \\
\text { range }\end{array}$ & $\begin{array}{c}\text { The } D_{\mathrm{V}} \text { expression } \\
\left(\mathrm{cm}^{2} \mathrm{~s}^{-1}\right)\end{array}$ & References \\
\hline iron $(\gamma \mathrm{Fe})$ & $700-1000{ }^{\circ} \mathrm{C}$ & $0.5 \exp (-209 / R T)$ & Wang [22] \\
\hline Fe-Ni 25 & $950-1200{ }^{\circ} \mathrm{C}$ & $0.011 \exp (-143 / R T)$ & Netter [21] \\
\hline Fe-Ni 36 & $600-1000{ }^{\circ} \mathrm{C}$ & $26.8 \exp (-261.4 / R T)$ & This work \\
\hline Fe-Ni 50 & $950-1200{ }^{\circ} \mathrm{C}$ & $3.1 \exp (-212.8 / R T)$ & Netter [21] \\
\hline Fe-Ni 75 & $950-1200{ }^{\circ} \mathrm{C}$ & $0.048 \exp (-163.9 / R T)$ & Netter [21] \\
\hline nickel & $1000-1200{ }^{\circ} \mathrm{C}$ & $2.3 \times 10^{6} \exp (-376.2 / R T)$ & Pfeiffer [23] \\
\hline nickel & $700-1000{ }^{\circ} \mathrm{C}$ & $0.2 \exp (-192 / R T)$ & Wang [22] \\
\hline nickel & $800-1225{ }^{\circ} \mathrm{C}$ & $1.4 \exp (-218.6 / R T)$ & Vladimirov [24] \\
\hline
\end{tabular}

segregation of phosphorus, boron, nitrogen and sulfur on the surface can modify the thermodynamics of the segregation according to the model developed by M. Guttmann [20] ; but, it seems logical to assume that in the presence of a multispecies segregation, the kinetic relation of each species could also be altered. In the present case, if we refer to the value calculated from the isothermal kinetic relation at $600{ }^{\circ} \mathrm{C}$, it is found that the cosegregation of phosphorus, boron, nitrogen and sulfur accelerates the sulfur diffusion in the Fe-Ni 36 alloy. The same observation has been made during the isothermal kinetic relations at $700{ }^{\circ} \mathrm{C}$ : the observed relation during the first stage of the annealing where the phosphorus cosegregates, is faster than that recorded later. Hence, the value retained as representative of sulfur diffusion has been calculated from the second slope of the experimental curve.

The diffusion characteristics of sulfur in the $\mathrm{Fe}-\mathrm{Ni}$ 36 alloy do not represent an important difference from the values associated with the other $\mathrm{Fe}-\mathrm{Ni}$ alloys [21], the iron $\gamma \mathrm{Fe}$ [22] and the nickel [22-24] (see Tab. III). But, the obtained values for the FeNi 36 alloy confirm the remark made by Netter et al. [21] : there is no steady variation of the pre-exponential $\left(D_{0}\right)$ and the activation energy $(Q)$ versus the alloy composition. On the other hand, in the $\log \left(D_{0}\right)$ versus $\left(Q / T_{\mathrm{M}}\right)$ diagram shown in figure 6 ( $T_{\mathrm{M}}$ is the melting point of the alloys), the value of the Fe-Ni 36 alloy is relatively distant from the curve determined by Netter [21] and we think that this is what caused the inaccuracy of the $D_{0}$ and $Q$ values.
The calculated activation energy value suggests a vacancy mechanism for the diffusion of sulfur in the Fe-Ni 36 alloy. The published values of formation energy $\left(E^{\mathrm{F}}=1.57 \mathrm{eV}\right)$ and the migration energy $\left(E^{\mathrm{M}}=1.10 \mathrm{eV}\right)$ of vacancies in the $\mathrm{Fe}-\mathrm{Ni}$ alloys do not depend on the alloy composition in the range 50$100 \%$ of nickel [26]. Assuming that these results are valid for a $\mathrm{Fe}-\mathrm{Ni} 36$ alloy, the activation energy $(261.4 \mathrm{~kJ} / \mathrm{mole})$ for sulfur in this alloy is in good agreement with the value $(258.4 \mathrm{~kJ} / \mathrm{mole})$ obtained from the sum $E^{\mathrm{F}}+E^{\mathrm{M}}$.

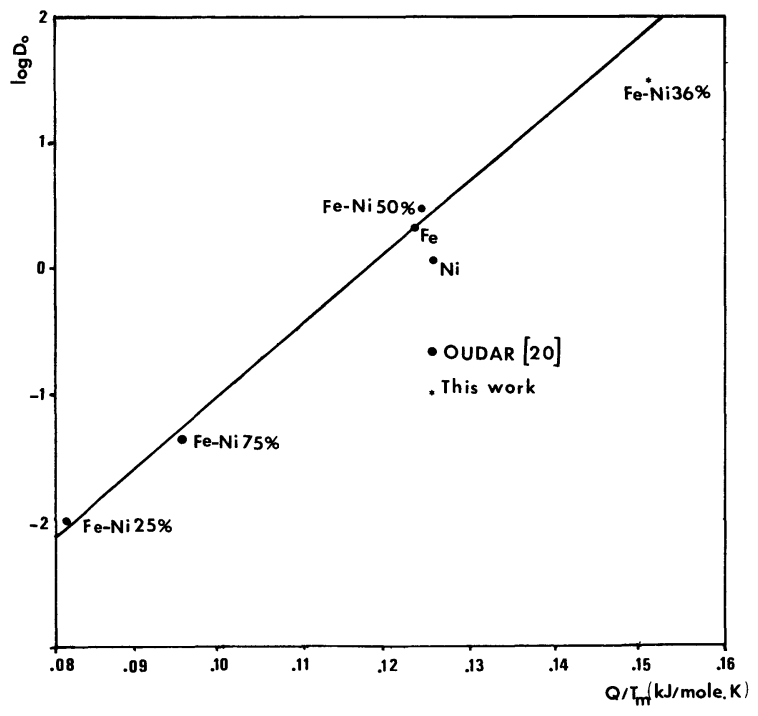

Fig. 6. - Variation of $\log \left(D_{0}\right)$ as a function of $\left(Q / T_{\mathrm{M}}\right)$. 


\section{Conclusions.}

Sulfur segregates to the surface of the Fe-Ni 36 alloy and the similitudes with the Ni-S system are very good. Namely, competition between sulfur and phosphorus occurs at low temperatures (until $700{ }^{\circ} \mathrm{C}$ ), after which the sulfur segregates exclusively.

The exploitation of the segregation kinetic laws determined by AES measurements permits calculation of the characteristics of the sulfur bulk diffusion in the Fe-Ni 36 alloy. Except for the value published by Pfeiffer [23], the activation energy determined experimentally $(261.4 \mathrm{~kJ} / \mathrm{mole})$ is the highest of those determined for pure iron $(\gamma \mathrm{Fe})$, pure nickel, Fe-Ni 50 and Fe-Ni 75 alloys. Nevertheless, this value is still consistent with a vacancy diffusion mechanism.

These results have been obtained by the study of surface segregation which is faster than the methods currently used for diffusion studies; nevertheless, this method requires the existence of superficial segregation of the studied element and the existence of proper physicochemical boundary conditions to simplify the solution to the Fick's second equation.

The authors acknowledge the technical assistance of J. P. Roche for Auger electron analysis and the collaboration of J. P. Colin of Imphy S.A. Research Center.

\section{References}

[1] Marcus, P., Tessier, A. and Oudar, J., Surf. Sci. 129 (1983) 432.

[2] White, C. L., Schneibel, J. H. and PadgetT, R. A., Metall. Trans. A 14 (1983) 595.

[3] IMPHY, S. A. (internal report) $\mathrm{n}^{\circ} 845$.

[4] ArabczyK, W., Militzer, M., Mussig, H. and WIETING, J., Scr. Metall. 20 (1986) 1549.

[5] Henessen, K., Keller, H. and Yiefhaud, H., Scr. Metall. 18 (1984) 1319.

[6] Rolland, A. and Bernardini, J., Scr. Metall. 19 (1985) 839.

[7] BRAilsford, A. D., Surf. Sci. 94 (1980) 387.

[8] Lagues, M., Phlips. Res. Rep. Suppl. 5 (1976).

[9] LeA, C. and SEAH, M. P., Philos. Mag. 35 (1977) 213.

[10] MCLEAN, D., Grain boundaries in metals (Clarendon press), Oxford (1957) 116.

[11] Colin, J. P., Private communication.

[12] Marcus, P. and OlefJord, I., Corrosion 42 (1986) 91.

[13] Dumoulin, P., Guttmann, M., Foucault, M., PAlmier, M., WAYMAN, M. and BisCondi, M., Met. Sci. 14 (1980) 1.

[14] Palmberg, P. W., Riach, G. E., Weber, R. E. and MCDonAld, N. C., Handbook of Auger elec- tron spectroscopy, Electronics Industries Inc. (1972).

[15] LARERE, A., Thèse doctorat, Université Paris Sud (1983).

[16] Reed, R. P. and Schramm, R. E., J. Appl. Phys. 9 (1969) 3453.

[17] Ferhat, F., Roptin, D. and Saindrenan, G., Scripta Metall. 22 (1988) 223.

[18] Roptin, D. and Saindrenan, G., To be published.

[19] Netter, P., Barbouth, N., Mem. Sci. Rev. Met. 80 (1983) 701.

[20] Guttmann, M., Atomistic of fracture, Calcatoggiu (France) 1 (1981).

[21] Netter, P., Barbouth, N. and Oudar, J., C.R. Acad. Sc. Paris (1982) 867.

[22] Wang, S. J. and GRABKe, H. J., Z. Mettalkd 61 (1970) 597.

[23] Pfeiffer, I., Z. Mettalkd 46 (1955) 516.

[24] Vladimirov, A. B., Kaigorov, V. N., Klotzman, S. M. and Trakhtenberg, I. S., Fiz. Rev. Met. 39 (1975) 319.

[25] AddA, Y. and Philibert, J., La diffusion dans les solides, Tome 1 (P.U.F.) Paris (1966), 485.

[26] Caplain, A. and Chambron, W., Acta Met. 25 (1977) 1001 